\title{
EL DERECHO DE LAS PERSONAS CON DISCAPACIDAD A GOZAR DEL MÁS ALTO NIVEL DE SALUD POSIBLE
}

\section{THE RIGHT OF PERSONS WITH DISABILITIES TO ENJOY THE HIGHEST ATTAINABLE STANDARD OF HEALTH}

\section{María Florencia Blanco Pighi ${ }^{1}$}

DOI: https://doi.org/10.37767/2591-3476(2020)35

\section{Comentario a}

Artaza, Ramón Alberto c/ Administración Provincial Del Seguro De Salud (A.P.R.O.S.S) AMPARO (LEY 4915)

Cámara Contencioso-Administrativa de 2da Nominación

(Poder Judicial de la Provincia de Córdoba)

RESUMEN:

El fallo judicial de análisis versa sobre el reconocimiento del derecho subjetivo de una persona adulta mayor que padece de hipoacusia bilateral profunda, a gozar del más alto nivel posible de salud. En ese contexto, se considera el alcance que debe tener el derecho a la salud de las personas con discapacidad, sobre todo en términos de accesibilidad, y el rol que cumple el Estado como garante del mismo.

\section{ABSTRACT}

The judicial ruling of analysis deals with the recognition of the subjective right of an elderly person suffering from profound bilateral hearing loss to enjoy the highest possible level of health. In this context, the scope of the right to health of people with disabilities, especially in terms of accessibility, and the role of the State as guarantor of it must be considered.

PALABRAS CLAVE: Discapacidad; hipoacusia neurosensorial bilateral profunda; derecho a la salud; protección constitucional; acción de amparo.

KEY WORDS: Disability; profound bilateral sensorineural hearing loss; right to health; constitutional protection; legal protection action.

1 Abogada y Profesora en Ciencias Jurídicas, egresada de la Facultad de Derecho de la Universidad Nacional de Córdoba. Diplomada en Derecho de las Familias (UNC). Adscripta de la Cátedra "B" de Privado VII, carrera de Abogacía, Facultad de Derecho U.N.C. Docente de la materia Política y Derecho Educacional del Profesorado en ciencias jurídicas de la Facultad de Derecho (UNC). Jefa de Trabajos prácticos de la Cat. "A" en la materia Privado VIII, Facultad de Derecho y Ciencias Sociales en la U.C.C.- Correo electrónico: florblancopighi@gmail.com. ORCID iD: https://orcid.org/0000-0001-9324-4036 


\section{Introducción}

El 15 de agosto de 2019 la Cámara en lo Contencioso Administrativo de Segunda Nominación de la ciudad de Córdoba, resolvió hacer lugar a la acción de amparo interpuesta en contra de una obra social reconociendo el derecho subjetivo del actor a la cobertura integral del implante coclear en su oído derecho.

Para así resolver, el tribunal se apartó de lo establecido por Resoluciones 101/07² (de tipo interna, emanada de la obra social) y 400/16³ del Ministerio de salud de la Nación, y fundamentó la sentencia en normativa nacional (Constitución Nacional y leyes especiales en la materia) y en tratados internacionales en los que la Republica Argentina es parte.

Del análisis normativo efectuado, la cámara sostuvo que la denegación de cobertura con fundamento en las resoluciones mencionadas, implicaba incurrir en una omisión lo suficientemente lesiva del derecho constitucional a la salud, impidiendo al actor el desarrollo de una vida digna en plenitud personal y con su entorno.

En este marco, el presente artículo tiene en miras un análisis de la normativa en juego, para poder vislumbrar si la resolución en cuestión es acorde a derecho y, en consecuencia, determinar si la misma responde a una aplicación armónica de la legislación nacional e internacional vigente en nuestro país.

\section{Reseña del caso. La controversia.}

La parte actora con motivos de su discapacidad (hipoacusia bilateral profunda) promueve acción de amparo en contra de la obra social de la cual es afiliado, a los fines de obtener una cobertura integral del implante coclear en oído derecho, con más todas las prestaciones accesorias que hacen a su debido funcionamiento ya que ello le permitiría transformar los sonidos en estímulos eléctricos a su cerebro, mejorando así su calidad de vida. Argumentó también que la presente acción se inició debido a los fracasos extrajudiciales y administrativos para lograr la mentada cobertura.

Por su parte, la obra social demandada, manifiesta que el amparista es portador de un implante coclear en el oído izquierdo provisto por la primera y funda la falta de cobertura del segundo implante en la Resolución 101/07 que impone un límite de edad de 60 años para el receptor. Asimismo, refiere que ha existido una falta de informes y pedidos médicos por parte de prestadores de la obra social que dificulta la recepción del pedido del actor.

Sin perjuicio de ello, en los autos no se controvierte ni la calidad de afiliado del actor, la enfermedad que padece, su condición de persona con discapacidad, ni la existencia de otro implante cuya cobertura procuró la obra social demandada.

De las constancias de la causa adquiere relevancia, la discusión sobre la normativa aplicable: ¿es posible negar el derecho a la salud del actor basándose en una resolución emanada de la propia parte demandada?

\section{Las normas en contradicción y la supremacía constitucional}

Que, así las cosas, nos encontramos en una discusión de pleno derecho sobre la norma-

2 Esta resolución, al 18/05/2020, no se encuentra disponible en la página oficial de A.P.R.O.S.S. (http://www.apross.gov.ar/14-Resoluciones-Ano-2007.note.aspx)

3 Resolución disponible en: http://www.faosdir.org.ar/pdf/Resolucion400-2016-SSS.pdf (al 19/05/2020) 
tiva aplicable. La Cámara decidió hacer lugar al planteo del actor, entendiendo que encuentra protegido su derecho a la salud por la Constitución Nacional Argentina (art. 33), por tratados internacionales con jerarquía constitucional, a partir de su incorporación en el art. 75 inc. 22 (entre ellos: el art. 12 inc. c del Pacto Internacional de Derechos Económicos, Sociales y Culturales; el art. 4 inc. 1 y 5 inc. 1 de la Convención Interamericana de Derechos Humanos; el art. 6 inc. 1 del Pacto Internacional de Derechos Civiles y Políticos y los arts. 1, 3, 4, 25 y 28 de la Convención sobre los Derechos de las personas con discapacidad), por la Constitución de la Provincia de Córdoba (Art. 27 y 59), por la Ley Nacional № 25.415 del año 2001 (art. 4) y por la Ley Provincial Nº 9564 del año 2008 (art. 5).

Resulta de importancia recalcar que la Convención sobre los Derechos de las Personas con Discapacidad establece en su art. 1 que el propósito de la misma es promover, proteger y asegurar el goce pleno y en condiciones de igualdad, de todos los derechos humanos de las personas con discapacidad. En el marco de esta normativa, los Estados Partes se comprometen a asegurar y promover el pleno ejercicio de esos derechos humanos (art. 4) y "reconocen que las personas con discapacidad tienen derecho a gozar del más alto nivel posible de salud sin discriminación por motivos de discapacidad". A su vez, los Estados Partes se comprometen a asegurar el acceso de las personas con discapacidad a los servicios de salud.

En este sentido, el tribunal rechaza los argumentos de la parte demandada que sustentaba su negativa a otorgar la prestación requerida, en un límite de edad (60 años) establecido tanto en la Resolución interna N 101/07 como en la Resolución del Ministerio de Salud de la Nación 400/16.

Finalmente, es necesario hacer hincapié en que, una interpretación armónica de la normativa citada, que conforma en los términos del Tribunal interviniente "un bloque constitucional y legal", solo puede llevarnos en el mismo rumbo que la sentencia en análisis. El propio Tribunal establece en el voto de la Dra. Ortiz de Gallardo, en consonancia con fallos anteriores, que, "las leyes deben ser interpretadas en su letra y en su espíritu y con especial armonización con el resto de las normas que integran el ordenamiento jurídico"t.

\section{Algunas precisiones sobre la resolución}

En el caso en cuestión se desarrollan argumentos sustentados en normativa de jerarquía constitucional de gran valor, sin perjuicio de ello, podrían adicionarse algunos elementos de peso para fortalecer la decisión arribada.

En este sentido, podría hacerse hincapié en el art. 75 inc. 23 de nuestra Carta Magna le impone al Congreso de la Nación la obligación de "legislar y promover medidas de acción positivas que garanticen la igualdad real de oportunidades y de trato, y el pleno goce y ejercicio de los derechos reconocidos por esta Constitución y por los tratados internacionales vigentes sobre derechos de los niños, las mujeres, los ancianos y las personas con discapacidad...". Normativa que evidencia la manda constitucional de proteger a los ancianos y a las personas con discapacidad, ambas situaciones acaecidas en la situación analizada.

Por otro lado, si bien no se mencionan como argumentos de las partes ni del Tribunal, también correspondería la aplicación de las 100 Reglas de Brasilia (actualizadas en el año 
2018) ya que las personas con discapacidad son incluidas entre aquellos que, por su situación de vulnerabilidad, encuentran especiales dificultades para ejercitar con plenitud ante el sistema de justicia los derechos reconocidos por el ordenamiento jurídico ${ }^{5}$. Más aun teniendo en cuenta la doble situación de vulnerabilidad del actor, quien es un adulto mayor y una persona con discapacidad.

Ante este panorama, adquiere relevancia el rol que asuma el Estado, ya que de ello dependerá la única posibilidad de crear las condiciones para un derecho a la salud sustentable ${ }^{6}$. Es decir, que en el marco de la normativa vigente, el Estado adquiere el rol de garante de un acceso real a las prestaciones de salud ${ }^{7}$.

Sin dudas, la regulación vigente no implica entender el derecho a la salud como un derecho absoluto, que no puede ser regulado, sino que debemos realizar una interpretación armónica de la normativa en juego, partiendo de un piso mínimo aceptable, que en nuestro caso está dado por las normas que conforman el bloque de constitucionalidad ${ }^{8}$.

Este argumento ha sido reforzado por la Corte Interamericana de Derechos humanos al establecer que se debe realizar una interpretación sistemática, teleológica y evolutiva, recurriendo al corpus iuris internacional en la materia, para poder dar contenido específico al alcance de los derechos tutelados por la Convención?

\section{El más alto nivel posible de salud}

Cabe preguntarnos ahora, ¿qué debe ser entendido por el "más alto nivel posible de salud" que expresa el art. 25 de la Convención sobre los Derechos de las Personas con Discapacidad?

Lo primero que debe aclararse es que, este concepto, no se encuentra únicamente contemplado en la convención mencionada, sino que también se encuentra regulado en el Pacto Internacional de Derechos Económicos, Sociales y Culturales (Art. 12, apartado $1^{\circ}$ ).

El Consejo Económico y Social de Naciones Unidas ha dicho que: "el concepto del "más alto nivel posible de salud", tiene en cuenta tanto las condiciones biológicas y socioeconómicas esenciales de la persona como los recursos con que cuenta el Estado (...). Por lo tanto, el derecho a la salud debe entenderse como un derecho al disfrute de toda una gama de facilidades, bienes, servicios y condiciones necesarios para alcanzar el más alto nivel posible de salud"mo.

Se ha dicho también, en este sentido, que se reconoce que el derecho a la salud, abarca una amplia gama de factores socioeconómicos que promueven las condiciones, gracias a las cuales las personas pueden llevar una vida sana, haciendo ese derecho extensivo a los factores determinantes básicos de la salud, como la alimentación y la nutrición, la

\footnotetext{
5100 Reglas de Brasilia. Disponible en: https://www.acnur.org/fileadmin/Documentos/BDL/2009/7037.pdf

6 URBINA, PAOLA ALEJANDRA. Estado y salud en Argentina: una aproximación histórica. Disponible en: http://www.salud.gob.ar/dels/entradas/estado-ysalud-en-argentina-una-aproximacion-historica (Consultado el 18/05/2020).

7 CLERICO, LAURA. (2009) ¿El argumento del federalismo vs. el argumento de igualdad? El derecho a la salud de las personas con discapacidad. Revista Jurídica de la Universidad de Palermo. Pág. 2. Disponible en: https://www.palermo.edu/derecho/revista_juridica/pub-11/11Juridica05.pdf (consultada el 18/05/2020). 8 OP. CLERICO. Pág. 4.

9 Caso Poblete Vilches y otros c/ Chile. Disponible en: http://www.corteidh.or.cr/docs/casos/articulos/seriec_349_esp.pdf (fecha de consulta: 19/05/2020). 10 Observación General N ${ }^{\circ} 14$ del Consejo Económico y Social de Naciones Unidad. El derecho al disfrute del más alto nivel posible de salud: 11/08/2000. E/C.12/2000/4 CESCR OBSERVACION GENERAL 14. (General Comments). Disponible en: https://www.acnur.org/fileadmin/Documentos/BDL/2001/1451. pdf (fecha de consulta: 18/05/2020).
} 
vivienda, el acceso a agua limpia potable y a condiciones sanitarias adecuadas, condiciones de trabajo seguras y sanas y un medio ambiente sano. Es decir que, el Comité de Naciones Unidas, interpreta el derecho a la salud, como un derecho inclusivo que no sólo abarca la atención de salud oportuna y apropiada sino también los principales factores determinantes de la salud ${ }^{11}$.

Esta normativa internacional, impone a los Estados Partes la obligación de respetar y permitir el acceso al derecho a la salud, a todos sus habitantes, sin poder aplicar ningún tipo de medida discriminatoria, generando una efectiva igualdad de acceso al derecho a la salud.

A su vez, la Corte Interamericana de Derechos Humanos ha dicho que "todo ser humano tiene derecho al disfrute del más alto nivel posible de salud que le permita vivir dignamente, entendida la salud no sólo como la ausencia de afecciones o enfermedades, sino también de un estado completo de bienestar físico, mental y social, derivado de un estilo de vida que permita alcanzar a las personas un balance integral'm2.

Así las cosas, el derecho a gozar del más alto nivel posible de salud implica ampliar el concepto de salud, teniendo en miras el proporcionado por la Organización Mundial de la Salud, entendida como "...un estado de perfecto (completo) bienestar físico, mental y social, y no sólo la ausencia de enfermedad"13. Lo cual impone una obligación a los Estados Partes de asegurar el efectivo acceso y goce de sus habitantes de este estado perfecto 0 completo de bienestar físico.

Podemos decir entonces que, el más alto nivel posible de salud, dependerá en cada caso concreto, y se evidenciará en un estado de bienestar general, que no implica únicamente "estar sano" y que se traduce en el mejor estado al que puede llegar esa persona, según sus circunstancias particulares. No quedan dudas que, en el caso en cuestión, este más alto nivel posible de salud se traduce en poseer ambos implantes cocleares que le permitirán al actor llevar adelante una vida de relación adecuada, en todo tipo de ambientes, pudiendo gozar de sus derechos en plenitud.

\section{Presunción de inconstitucionalidad}

Una cuestión interesante que surge del fallo en análisis, que trae a colación una consolidada doctrina del Alto Tribunal Argentino que establece que, en los casos en los que se impugna una categoría infra constitucional basada en un criterio etario, corresponde considerarla sospechosa de discriminación y portadora de una presunción de inconstitucionalidad que corresponde a la parte demandada levantar ${ }^{14}$.

Es decir que, cuando opere esta presunción de inconstitucionalidad sobre la normativa cuya aplicación se pretende, será la parte demandada quien deba probar que, en el caso concreto, dicha norma no ofende a la Constitución Nacional. Lo que no ocurre en el caso de marras, donde se pretende la mera aplicación de las resoluciones mencionadas, sin acreditar este extremo.

\footnotetext{
11 GARAY, OSCAR ERNESTO. Derecho a la salud II. DELS. Disponible en: http://www.salud.gob.ar/dels/entradas/derecho-la-salud-ii (fecha de consulta: 18/05/2020).

12 Caso Poblete Vilches y otros c/ Chile. Disponible en: http://www.corteidh.or.cr/docs/casos/articulos/seriec_349_esp.pdf(fecha de consulta: 19/05/2020).

13 Organización Panamericana de Salud. Disponible en: https://www.paho.org/arg/index.php?option=com_content\&view=article\&id=28:preguntasfrecuentes\&Itemid=142 (Fecha de consulta: 18/05/2020).

14 Fallos: 327:5118
} 
Es preciso recordar que el art. 31 de la Carta Magna resulta sumamente claro: "Esta Constitución, las leyes de la Nación que en su consecuencia se dicten por el Congreso y los tratados con las potencias extranjeras son la ley suprema de la Nación..." por lo cual, ninguna ley o, en este caso, resolución, podría contrariar lo establecido en nuestras normas constitucionales.

El tribunal interviniente, menciona que el tope de edad establecido en las mismas no tiene ningún sustento fáctico ni legal que lo avale, y ni siquiera se relaciona con la edad jubilatoria establecida para los varones. Razón por la cual, la vulneración del derecho a la salud y la inconstitucionalidad de la norma que así lo regula, deviene evidente.

\section{A modo de conclusión}

Es necesario puntualizar, en primer lugar, que el derecho a la salud no está expresamente establecido en nuestra Constitución Nacional, pero si ha sido receptado por los tratados internacionales con jerarquía constitucional, razón por la cual resulta de aplicación directa el art. 28 C.N. en cuanto establece que los derechos y garantías consagrados en el texto constitucional, no podrán ser alterados por las leyes que reglamenten su ejercicio. En el caso de marras, ni siquiera estamos ante una ley, en el sentido estricto de la misma, sino de dos resoluciones emanadas de autoridades administrativas en el orden provincial y nacional, respectivamente.

Por lo tanto, resulta indiscutible que el derecho a la salud ha sido ampliamente reconocido en nuestro país, tanto en la órbita nacional como internacional, sin embargo, lo que todavía parece ser cuestionado es su operatividad.

Internacionalmente, el Estado Argentino se ha comprometido a asegurar y garantizar el acceso a la salud de todos sus habitantes y ha reforzado, si se quiere, dicho compromiso cuando se trate de personas en especial situación de vulnerabilidad.

La protección del derecho de salud, abarca el deber de los Estados por adoptar todas aquellas medidas que garanticen un acceso igualitario a los servicios de salud, incluso cuando sean suministrados por terceros, lo cual puede traducirse en la adopción de acciones positivas que permitan asistir a las personas y comunidades en el disfrute efectivo del derecho a la salud. Que, si los Estados así no lo hiciesen, serán responsables ante la comunidad internacional por las vulneraciones al derecho a la salud que pudieren acaecer.

En el fallo en análisis resulta claro que debemos velar porque el actor obtenga el nivel de salud más alto posible, y, de los informes médicos presentados, surge que el mismo solo será alcanzado con el segundo implante coclear. Resulta evidente, a los ojos del Tribunal, que el derecho a la salud, entendido como ese estado de bienestar descripto por la propia O.M.S., en el caso analizado solo quedará garantizado haciendo lugar a la acción de amparo interpuesta.

Finalmente, cabe concluir que el Estado Argentino ha asumido un compromiso a nivel internacional, por velar por el cumplimiento de los tratados de derechos humanos que ha ratificado y que, en muchos casos, tienen jerarquía constitucional, y que este compromiso atañe a los tres poderes del Estado, no pudiendo el Poder Judicial hacer caso omiso a esta obligación. Que este mandato constitucional, ha sido reforzado por las 100 reglas 
de Brasilia, que también deben ser tenidas en cuenta a la hora de permitir el acceso a la justicia de personas en estado de vulnerabilidad, tal y como ocurre en el presente caso, que estamos ante un adulto mayor con discapacidad, es decir, una persona en situación de hiper vulnerabilidad.

Así las cosas, cada miembro del Estado deberá dar cumplimiento a este compromiso asumido, para lograr un efectivo acceso al derecho a la salud, y los operadores del sistema de justicia, tenemos un rol fundamental en este proceso. 